\title{
Effective Chemopreventive Activity of Genistein against Human Breast Cancer Cells
}

\author{
Yun-Hee Shon ${ }^{1}$, Sun-Dong Park ${ }^{2}$ and Kyung-Soo Nam ${ }^{3, *}$ \\ ${ }^{1}$ Intractable Disease Research Center, Dongguk University, Gyeongju 780-714, Republic of Korea \\ ${ }^{2}$ Department of Herbal Pharmacology, College of Oriental Medicine and Cardiovascular Medical Research Center, \\ Dongguk University, Gyeongju 780-714, Republic of Korea \\ ${ }^{3}$ Department of Pharmacology, College of Medicine, Dongguk University, Gyeongju 780-714, Republic of Korea
}

Received 7 March 2006, Accepted 2 May 2006

\begin{abstract}
Chemopreventive and cytotoxic effect of genistein against human breast cancer cell lines was investigated. Genistein inhibited cell proliferation in estrogen receptor-positive (MCF-7) and estrogen receptor-negative (MDA-MB-231) human breast carcinoma cell lines. Cytochrome $\mathbf{P 4 5 0}$ (CYP) 1A1-mediated ethoxyresorufin $O$-deethylase (EROD) activity was inhibited by genistein in a concentrationdependent manner. Genistein significantly inhibited 12- $O$ tetradecanoylphorbol-13-acetate (TPA)-induced cyclooxygenase- 2 activity and protein expression at the concentrations of $10(p<0.05), 25(p<0.05)$ and $50 \mathrm{mM}(p<0.01)$. In addition, ornithine decarboxylase (ODC) activity was reduced to $53.8 \%$ of the control after $6 \mathrm{~h}$ treatment with $50 \mathrm{mM}$ genistein in MCF-7 breast cancer cells. These results suggest that genistein could be of therapeutic value in preventing human breast cancer.
\end{abstract}

Keywords: Breast cancer, Cyclooxygenase-2, Cytochrome P450 1A1, Genistein, Ornithine decarboxylase

\section{Introduction}

Breast cancer is the most common malignancy in women world-wide and continues to be about 48,000 women dying for every year. A major effort to reduce breast cancer mortality and morbidity is focused on development of better breast cancer chemoprevention (Steele, 2003; Kim et al., 2004). Although pharmaceutical agents have therapeutic and preventive roles in breast cancer, the use of compounds from natural products to prevent breast cancer is currently being explored.

\footnotetext{
*To whom correspondence should be addressed.

Tel: 82-54-770-2412; Fax: 82-54-770-2477

E-mail : namks@dongguk.ac.kr
}

Cytochrome P450 (CYP) 1A1 plays a key role in estrogen metabolism, catalyzing the conversion of $17 \beta$-estradiol to hydroxylated estrogen. It has been shown that estrogen exposure is directly associated with risk for developing breast cancer. A prolonged or increased exposure to estrogen is associated with an increased risk for developing breast cancer, whereas reducing exposure is thought to be protective (Begg et al., 1987). Therefore, alterations in the activity of CYP 1A1 could plausibly lead to a change in the levels of estrogen and, ultimately, could affect breast cancer risk. CYP 1A1 expression has been detected in cancerous breast tissue (Huang et al., 1996) and can be induced in human-breast-derived cell lines (Spink et al., 1998).

Cyclooxygenase (COX) is considered important in breast carcinogenesis. The COX-2 enzyme is expressed more in breast cancers than in normal breast tissue (Mazhar et al., 2006). COX-2 inhibition may have a role in breast cancer prevention. COX-2 inhibitors were effective in the prevention of breast cancer in several animal models (Schrey et al., 1995).

The enhancement of ODC activity by carcinogens or oncogenes leads to sequential increases in the concentrations of putrescine, spermidine and spermine. The structural characteristics and charge specificity of polyamines enable them to enter into hydrophobic and electrostatic interactions with macromolecules, DNA, RNA and proteins, and alter their three-dimensional structure and biological function (Thomas and Kiang, 1987). ODC activity is higher in tumor than in nontumor tissue, and elevated ODC activity and polyamine levels are biomarkers for human breast carcinoma (Mimori et al., 1998; Canizares et al., 1999).

Genistein, a natural flavone found in soy, has received much attention as a potential anticancer agent due to its diverse effects on the cellular processes. Several possible mechanisms for the anticancer effects of genistein include topoisomerase II inhibition, angiogenesis and protein tyrosine kinase (Fotsis et al., 1997). 
The present study investigated the effect of genistein on the proliferation of breast cancer cells and activities of CYP 1A1, COX-2 and ODC.

\section{Materials and Methods}

Chemicals. Genistein, RPMI 1640 medium and bicinchoninic acid protein assay kit were purchased from Sigma Chemical Co.. L-[1${ }^{14} \mathrm{C}$ ]ornithine was purchased from Amersham Biosciences.

Cell proliferation assay. Estrogen receptor-positive MCF-7 and estrogen receptor-negative MDA-MB-231 cells were plated at an initial cell concentration of $0.5 \times 10^{4}$ cells per well of 96-well plate in RPMI 1640 medium supplemented with $10 \%$ fetal bovine serum for $24 \mathrm{~h}$ and treated with $50 \mathrm{mM}$ genistein for 2, 4 and 6 days. Measurement of cell proliferation was determined using 3-4,5dimethylthiazol-2-yl-2,5-diphenyltetrazolium bromide (MTT) assay.

Animals and treatment. Male Sprague-Dawley rats (body wt 130$150 \mathrm{~g})$ from the Dae-Han Laboratory Animal Research Center (Eumsung, Korea) were used for the experiment. Animals were pretreated with $\beta$-naphthoflavone (three daily intraperitoneal injection of $80 \mathrm{mg} / \mathrm{kg}$ body wt) for CYP $1 \mathrm{~A} 1$. The rats were sacrificed after an overnight fast by cervical dislocation $24 \mathrm{~h}$ after the last injection. The liver was homogenized with $0.15 \mathrm{M} \mathrm{KCl}$ buffer ( $\mathrm{pH} 7.0)(5 \mathrm{ml} / \mathrm{g}$ of tissue) followed by centrifugation at $9,000 \times \mathrm{g}$ for $20 \mathrm{~min}$. The microsomal pellets were obtained by recentrifugation at $27,000 \times g$ for $20 \mathrm{~min}$. The protein contents of microsomal fractions were determined using a bicinchoninic protein assay kit with bovine serum albumin as the standard.

Inhibition of CYP 1A1 activity. CYP 1A1 activity was monitored by assessing ethoxyresorufin $O$-deethylase (EROD) activity (Shon et al., 2004). Reaction mixture contained microsomal protein, 0.05 $\mathrm{M}$ Tris-HCl buffer (pH 7.5), bovine serum albumin, $0.25 \mathrm{M} \mathrm{MgCl}_{2}$, NADPH-generating system (NADP, glucose-6-phosphate and glucose-6-phosphate dehydrogenase), ethoxyresorufin and various concentrations of samples. After incubating at $37^{\circ} \mathrm{C}$ for $4 \mathrm{~min}$, the reactions were terminated by the addition of $2 \mathrm{ml}$ of methanol. The formation of resorufin was determined fluorometrically $(550 \mathrm{~nm}$ excitation and $585 \mathrm{~nm}$ emission) with spectrofluorometer (BIOTEK).

COX-2 expression (Western Blotting). MDA-MB-231 cells were plated in 12 well plate and grown to subconfluency. For treatment with genistein and 12-O-tetradecanoylphorbol-13-acetate (TPA), subconfluent cells were washed and changed to serum-free medium containing $0.1 \%$ bovine serum albumin for $24 \mathrm{~h}$. Incubation was continued with or without genistein and TPA for $30 \mathrm{~h}$. Cells were harvested and lysed as described previously (Liu et al., 1993). The protein from cell lysates was electrophoresed on a 9\% SDSpolyacrylamide gel and then electrophoretically transferred to a polyvinylidene difluoride membrane. The membrane was treated with $5 \%$ non-fat milk for $1 \mathrm{~h}$ to block non-specific binding and probed with primary antibodies to COX-2 and actin at a final dilution of $1: 1,000$. Primary antibodies were detected using biotin-rabbit anti-mouse Ig GAM $(\mathrm{H}+\mathrm{L})$ and alkaline phosphate-conjugated streptavidin and visualized by 4-nitro blue tetrazolium chloride/5bromo-4-chloro-3-indolyl-phosphate substrate (Promega).

Assay of COX-2 enzymatic activity. Lysates of MDA-MB-231 cells were prepared as described above. COX-2 enzymatic activity was measured using prostaglandin (PG) $\mathrm{E}_{2}$ Biotrak enzyme immunoassay kit (Amersham Biosciences) according to the manufacturer's protocol. The assay is based on competition between unlabelled $\mathrm{PGE}_{2}$ and a fixed quantity of peroxidaselabelled $\mathrm{PGE}_{2}$ for a limited number of binding sites on a $\mathrm{PGE}_{2}$ specific antibody. The anti- $\mathrm{PGE}_{2}$ antibody has $25 \%$ and $0.04 \%$ cross-reactivity with $\mathrm{PGE}_{1}$ and $\mathrm{PGE}_{2 \alpha}$.

Ornithine decarboxylase activity. MCF-7 breast cancer cells were plated at a density of $1 \times 10^{5}$ cells per well in 24-well tissue culture plates. After incubation at $37^{\circ} \mathrm{C}$ for $18 \mathrm{~h}$ in a $5 \%(\mathrm{v} / \mathrm{v}) \mathrm{CO}_{2}$ atmosphere, the media was removed and replaced with media containing TPA (200 nM) alone or TPA plus genistein $(1-50 \mu \mathrm{M})$ or $0.01 \mathrm{mM}$ difluoromethylornithine (DFMO) as a positive inhibitor of ODC. After an additional $6 \mathrm{~h}$ of incubation at $37^{\circ} \mathrm{C}$, the cells were washed twice with $\mathrm{Ca}^{2+}, \mathrm{Mg}^{2+}$-free phosphate-buffered saline (pH 7.4) and subjected to three freeze-thaw cycles. ODC activity was assayed directly in the 24-well plates by measuring the release of ${ }^{14} \mathrm{CO}_{2}$ from L-[1- $\left.{ }^{14} \mathrm{C}\right]$ ornithine (Shon and Nam, 2003). The amount of radioactivity was measured by liquid scintillation counter (Beckman LS 6500).

Statistical analysis. The data were analyzed for statistical significance using Student's $t$-test. $p$ Values less than 0.05 were considered to be significant.

\section{Results and Discussion}

Genistein inhibited the growth of estrogen-receptor positive MCF-7 and estrogen-receptor negative MDA-MB-231 cells (Fig. 1). Genistein exhibited similar growth-inhibitory pattern in both estrogen receptor-positive and estrogen receptornegative cells indicating a lack of estrogen receptor-induced sensitivity for genistein.

Treatment of genistein resulted in a concentration-dependent inhibition of CYP 1A1-mediated EROD activity (Fig. 2). CYP $1 \mathrm{~A} 1$ is the primary catalyst in the hydroxylation of $17 \beta-$ estradiol. Estrogen exposure is a known risk factor for human breast cancer. Estrogen promotes mitotic activity in the breast epithelium, increasing the risk of cancer (Pike et al., 1993). Furthermore, recent evidence indicates that estrogen metabolites may form DNA adducts, resulting in DNA mutations (Cavalieri et al., 1997). Concentrations of active estrogenic metabolites in the mammary tissues are critical for their biological activity. The influence of the CYP enzyme system on the biological effect of estrogen makes this enzyme predictor of breast cancer development as well as potential target for chemoprevention.

Treatment of MDA-MB-231 cells with TPA resulted in the increase of COX-2 protein levels. Genistein inhibited TPA- 


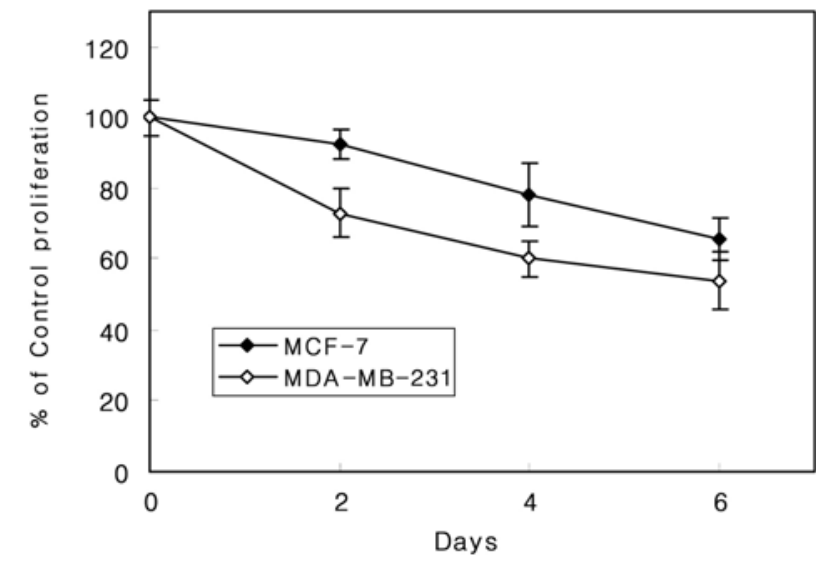

Fig. 1. Effect of genistein on proliferation of estrogen-dependent MCF-7 and estrogen-independent MDA-MB-231 human breast cancer cells. The percentage of cell proliferation with $50 \mu \mathrm{M}$ genistein (assays were carried out three times) was determined at 2,4 , and 6 days.

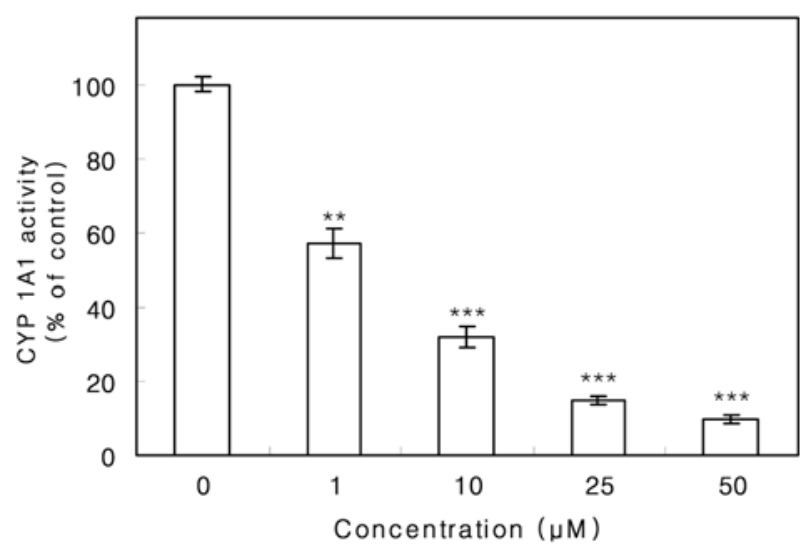

Fig. 2. Inhibition of CYP 1A1-mediated EROD activity using liver micromes derived from $\beta$-naphthoflavone-treated rats. The EROD activity was assessed with the indicated concentrations of genistein. Resveratrol (RV, 0.05 nmole) was used as a positive control in the assay. Data shown are mean values with bars indicating the SD of the mean $(\mathrm{n}=3) .{ }^{* *} p<0.01,{ }^{* * *} p<0.005$ compared with the control.

induced expression of COX-2 protein (Fig. 3A). To determine the relationship between COX-2 expression and COX-2 enzymatic activity, the production of $\mathrm{PGE}_{2}$ was measured. Fig. 3B shows that MDA-MB-231 cells produced a low basal $\mathrm{PGE}_{2}$ level and that treatment with TPA produced substantial increase after $30 \mathrm{~h}$. Genistein inhibited TPA-induced COX-2 activity in a dose-dependent manner (Fig. 3B). There is an increasing evidence suggesting that inhibitors of COX-2 activity can be effective as anti-inflammatory agents and also in the prevention and treatment of breast cancer, because $\mathrm{PGE}_{2}$ is mediator of inflammation (Kudo and Murakami, 2005), and chronic inflammation predisposes to carcinogenesis (Schrey et al., 1995). Therefore, agents that can inhibit COX-
(A)
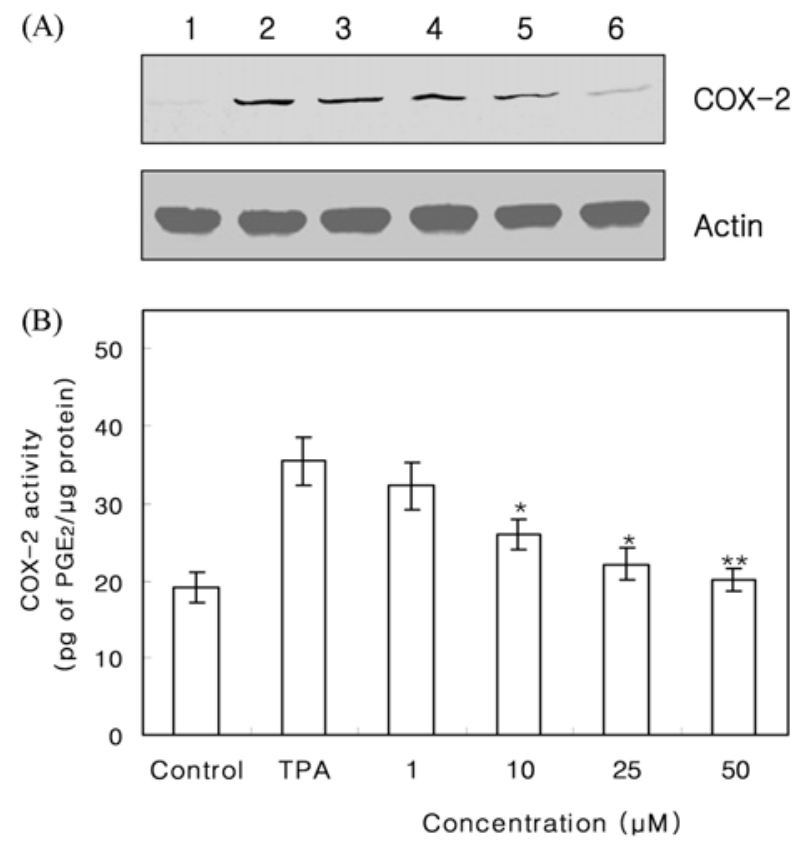

Fig. 3. Effect of genistein on expression (A) and activity (B) of COX-2. (A) Lane 1, untreated; lane 2, TPA $(150 \mathrm{nM})$ treated; lanes 3, 4, 5 and 6, TPA (150 nM) and genistein (1, 10, 25 and $50 \mu \mathrm{M}$, respectively) treated. (B) Data shown are mean values with bars indicating the $\mathrm{SD}$ of the mean $(\mathrm{n}=3) .{ }^{*} p<0.05$, ${ }^{* *} p<0.01$ compared with the control.

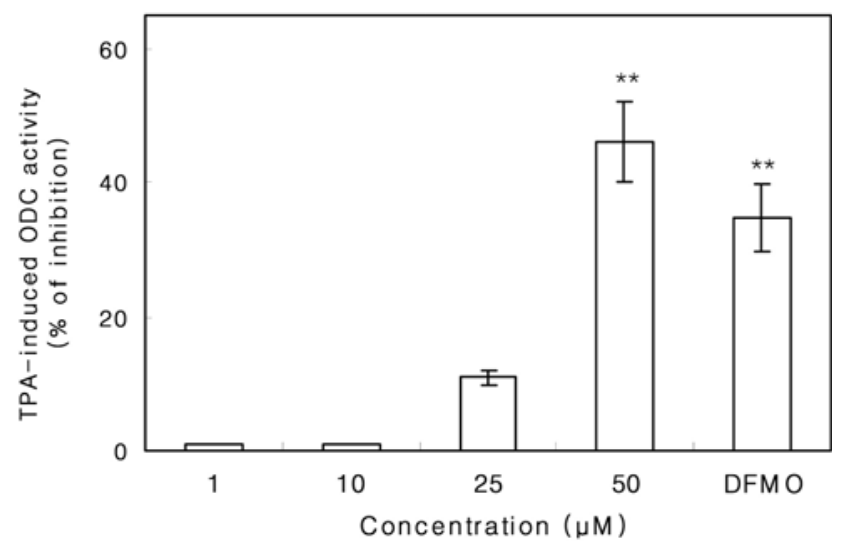

Fig. 4. Effect of genistein on TPA-induced ODC activity in MCF-7 human breast cancer cells. The ODC activity of control was $382 \pm 43 \mathrm{pmol}^{14} \mathrm{CO}_{2} / \mathrm{h} / \mathrm{mg}$ protein. Difluoromethylornithine (DFMO, $0.01 \mathrm{mM}$ ) was used as a positive control in the assay. Data shown are mean values with bars indicating the SD of the mean $(\mathrm{n}=3)$. ** $<0.01$ compared with the control.

2 activity might be useful for the inhibition of breast carcinogenesis.

Genistein exhibited suppressive effect on TPA-induced ODC activity of human breast cancer cells in a dose-dependent manner. Genistein at $50 \mu \mathrm{M}$ was more potent inhibitor of ODC activity than difluoromethylornithine (DFMO), a suicide 
inhibitor of ODC (Fig. 4). High expression of ODC characterizes breast cancer (Canizares et al., 1999). Several lines of evidence support an important role of the ODC activity in mammary carcinogenesis and breast cancer cell proliferation (Mimori et al., 1998; Canizares et al., 1999). ODC measurements may be used for predicting chemosensitivity of tumors cells and prognosis, and it has been suggested that ODC is a protooncogene. Over induction of ODC activity also results in stimulation of tumor promotion. Inhibition of ODC activity may be one of several targets involved in antipromoting effect of genistein in breast cancer developement.

These results suggest that genistein has chemopreventive potential against breast cancer by inhibiting the growth of human breast cancer cells, expression and enzymatic activity of COX-2 and CYP $1 \mathrm{~A} 1$ and ODC activities. To further development of genistein as breast cancer chemopreventive agent, mammary breast cancer test and clinical trials will be needed.

Acknowledgments This work was supported by the MRC program of MOST/KOSEF (grant \#: R13-2005-013-010030), Korea.

\section{References}

Begg, L., Kuller, L. H., Gutai, J. P., Caggiula, A. G., Wolmask, N. and Watson, C. G. (1987) Endogenous sex hormone levels and breast cancer risk. Genetic Epidemiol. 4, 233-247.

Canizares, F., Salinas, J., de las Heras, M., Diaz, J., Tovar, I., Martinez, P. and Penafiel, R. (1999) Prognostic value of ornithine decarboxylase and polyamines in human breast cancer: correlation with clinicopathologic parameters. Clin. Cancer Res. 5, 2035-2041.

Cavalieri, E. L., Stack, D. E., Devanesan, P. D., Todorovic, R., Dwivedy, I., Higginbotham, S., Johansson, S. L., Patil, K. D., Gross, M. L., Gooden, J. K., Ramanathan, R., Cerny, R. L. and Rogan, E. G. (1997) Molecular origin of cancer: catechol estrogen-3,4-quinones as endogenous tumor initiators. Proc. Natl. Acad. Sci. USA 94, 10937-10942.

Fotsis, T., Pepper, M. S., Aktas, E., Breit, S., Rasku, S., Adlercreutz, H., Wahala, K., Montesano, R. and Schweigerer, L. (1997) Flavonoids, dietary-derived inhibitors of cell proliferation and in vitro angiogenesis. Cancer Res. 57, 29162921.

Huang, Z., Fasco, M. J., Figge, H. L., Keyomarsi, K. and
Kaminsky, L. S. (1996) Expression of cytochromes P450 in human breast tissue and tumors. Drug Metab. Dispos. 24, 899905.

Kim, S. U., Lee, K. M., Park, S. K., Yoo, K. Y., Noh, D. Y., Choe, K. J., Ahn, S. H., Hirvonen, A. and Kang, D. H. (2004) Genetic polymorphism of glutathione $S$-transferase $\mathrm{P} 1$ and breast cancer risk. J. Biochem. Mol. Biol. 37, 582-585.

Kudo, I. and Murakami, M. (2005) Prostaglandin E synthase, a terminal enzyme for prostaglandin $\mathrm{E}_{2}$ biosynthesis. J. Biochem. Mol. Biol. 38, 633-638.

Liu, X. H., Wiley, H. S. and Meikle, A. W. (1993) Androgens regulate proliferation of human prostate cancer cells in culture by increasing transforming growth factor- $\alpha$ (TGF- $\alpha$ ) and epidermal growth factor (EGF)/TGF-2 receptor. J. Clin. Endocrinol. Metab. 77, 1472-1478.

Mazhar, D., Ang, R. and Waxman, J. (2006) COX inhibitors and breast cancer. Br. J. Cancer 94, 346-350.

Mimori, K., Mori, M., Shiraishi, T., Tanaka, S., Haraguchi, M., Ueo, H., Shirasaka, C. and Akiyoshi, T. (1998) Expression of ornithine decarboxylase mRNA and c-myc mRNA in breast tumors. Int. J. Oncol. 12, 597-601.

Pike, M. C., Spicer, D. V., Dahmoush, L. and Press, M. F. (1993) Estrogens, progestogens, normal breast cell proliferation, and breast cancer risk. Epidemiol. Rev. 15, 17-35.

Schrey, M. P. and Patel, K. V. (1995) Prostaglandin $E_{2}$ production and metabolism in human breast cancer cells and breast fibroblasts. Regulation by inflammatory mediators. $\mathrm{Br} . \mathrm{J}$. Cancer. 72, 1412-1419.

Shon, Y. H. and Nam, K. S. (2003) Inhibition of polyamine biosynthesis of Acanthamoeba castellanii and 12-O-tetradecanoylphorbol-13-acetate-induced ornithine decarboxylase activity by chitosanoligosaccharide. Biotechnol. Lett. 25, 701704.

Shon, Y. H., Nam, K. S. and Kim, M. K. (2004) Cancer chemopreventive potential of Scenedesmus spp. cultured in medium containing bioreacted swine urine. J. Microbiol. Biotechnol. 14, 158-161.

Spink, D. C., Spink, B. C., Cao, J. Q., DePasquale, J. A., Penteoost, B. T., Fasco, M. J., Li, Y. and Sutter, T. R. (1998) Differential expression of CYP1A1 and CYP1B1 in human breast epithelial cells and breast tumor cells. Carcinogenesis 19, 291-298.

Steele, V. E. (2003) Current mechanistic approaches to the chemoprevention of cancer. J. Biochem. Mol. Biol. 36, 78-81.

Thomas, T. and Kiang, D. T. (1987) Structural alterations and stabilization of rabbit uterine estrogen receptors by natural polyamines. Cancer Res. 47, 1799-1804. 